\title{
MISCDLANEA
}

\section{LA NARRATIVA COMO CLAVE PARA LA INVESTIGACIÓN ENFERMERA Y LOS CUIDADOS PROFESIONALES.}

OLIVÉ FERRER, M.C. ${ }^{a}$

CANGIANI FABBRO, M. R. ${ }^{b}$

a Escuela de Enfermería, Univerdidad de Barcelona

${ }^{\mathrm{b}}$ Departamento de Enfermagem Universidade Federal de São Carlos, São Carlos - S/P, Brasil

E-mail: olivecarmina@ub.edu 


\section{INTRODUCCIÓN}

En esta comunicación se presenta una narrativa dialógica, a modo de resultados y análisis, con la pretensión de entretejer un discurso científico que permita un diagnóstico y planificación de cuidados profesionales con una perspectiva sistémica, acorde al paradigma de la transformación y al siglo XXI.

Las historias que cuentan mujeres y hombres en el contexto profesional según (Guerreiro, 2008) son el retrato dialogado de sus experiencias, a la vez que nos dice que el diagnóstico de enfermería es la narrativa construida a partir de los recortes de estas historias.

Por su parte (Kérouac, 2007) nos dice que el paradigma de la transformación representa un cambio de mentalidad sin precedentes. Entiende cada fenómeno como único, es la base de una apertura de la ciencia enfermera hacia el mundo y ha inspirado las nuevas concepciones de la disciplina.

El modelo de enfermería de Mishel, (Bailey \& Stewart, 2005) cuyo concepto clave es la incertidumbre ante la enfermedad y que la función de la enfermera es valorar el grado de ésta para proporcionar unos cuidados profesionales que contribuyan a una adaptación harmónica, a una nueva perspectiva de vida y a un pensamiento probabilístico, conceptos que se desarrollaran en el transcurso de la comunicación.

\section{OBJETIVOS}

Identificar diagnósticos de enfermería acordes al paradigma de la transformación que emerjan de la narrativa de cuidadas, en este caso, personas afectadas de fibromialgia.

Contribuir al conocimiento científico enfermero, a través de la narrativa, con la posibilidad de ser llevado a la práctica de cuidados profesionales acordes al siglo XXI. 


\section{SUJETO Y MÉTODOS}

Se presenta una narrativa dialógica, con perspectiva emic i étic, proveniente de un afectado de fibromialgia (FM), afectado en sentido amplio (marido de una mujer diagnosticada de FM).

Enmarcada en la investigación cualitativa, etnografía y narrativa, se realiza una entrevista en profundidad abierta, se transcribe literal y se transforma en narrativa a través de la reflexión y la búsqueda de una estructura conceptual significativa.

\section{RESULTADOS Y ANÁLISIS SIMULTANEO}

\section{Para empezar}

Jordi se considera un tipo normal, algo testarudo, rodea los 50, se casó con una mujer activa allá por los años noventa del siglo pasado y tuvieron un hijo, todo marcha según sus perspectivas, se organizan para con el trabajo de cuidado y el trabajo remunerado; ella, Montse, pasa unas oposiciones y él complementa su jornada continuada con estudios universitarios, el hijo crece, y ella, cuando parecía que debía estar en plena forma empieza a sentirse mal, está agotada, tiene dolores... a lo que la ciencia médica responde con pruebas diversas que aportan poca claridad a su vivencia, parece que hay una anemia que lo podría justificar, aunque el tratamiento no mejora la sintomatología, y además hay que hacer pruebas familiares ya que se asocia a un componente genético; ella sigue con malestar, la primera etiqueta le permite no sentirse vaga, histérica... de momento, ya se sabe que son expresiones fáciles y más cuando encima ihaces buena cara! (Bailey \& Stewart, 2005) describen los conceptos del modelo Mishel, así conceptualiza la incertidumbre "como la incapacidad de determinar el significado de los hechos que guardan relación con la enfermedad" en esta primera etapa de la enfermedad es evidente, hay un malestar y no hay evidencia de diagnóstico clínico que lo justifique, y siguiendo a la misma autora es difícil que se dé apoyo social[1] y autoridad con credibilidad[2], necesarias para disminuir esta incertidumbre. 
"Yo todo este proceso lo he vivido como marido, con una primera etapa de escepticismo... pues yo no creía las señales que me enviaba mi mujer de que estaba jodida, recibía la información del profesional de la medicina que me decía nada, tu mujer está bien, yo le hago pruebas y está bien, no tiene nada y eso a mí me chocaba mucho porque nadie me había explicado que lo que le estaban haciendo era descartar posibles dolencias que pudieran tener la misma sintomatología (...) yo llegaba a la sana conclusión, que mi mujer está bien, no tiene un problema de enfermedad orgánica quiero decir, no le pasa nada, no le encuentran nada, eso no te lo decía una persona, te lo decían varios médicos."

\section{Malestar sin diagnóstico médico}

Seis años de incomprensión, de relación personal dura, seis años de especialista a especialista, análisis normales y sin un diagnóstico médico que permita entender y comprender el sufrimiento de ella y a la par, el de él y su hijo; seis años de recelos también por parte de la familia extensa. Una incertidumbre difícil de manejar en el tiempo y una relación familiar, a modo de sistema, que se resiente.

"El tema ya es más que conocido que muchas personas que están afectadas han vivido un periplo de profesional a profesional que incluso ha durado años, entonces claro... no es que una persona te diga que a tu mujer no le pasa nada, no, es que son varios que te lo dicen, entonces tú dices, a ver, no sé qué está pasando, pero no me cuadra (...) esto... explicado en diez minutos, no explica un proceso que puede durar meses y años, y durante este proceso sufrimos ambos, sufre ella porque ve que no la entiendo y sufro yo porque creo que me está enredando."

No se percibe autoridad con credibilidad, existe una vida en común de 15 años, un conocimiento previo y a Jordi no le encaja la vivencia de su esposa con las respuestas médicas, estamos en el siglo XXI, Internet está a su alcance, él trabaja en una biblioteca de la universidad, estudia derecho $y$, aunque desconoce términos médicos es capaz de manejarse por la red, buscar e interpretar la información, navega y encuentra mucha información ¿será 
demasiada? ¿Quién cree en Internet? ¿Qué papel ha jugado él hasta ahora?

"Tenemos que hacer algo... tenemos que encontrar a alguien que diga qué tienes, si es eso de la fibromialgia (FM) pues es eso de la FM y si es otra cosa, otra cosa, que te hagan un diagnóstico, que emitan un informe y lo presentamos en el trabajo, si no lo pasaremos mal, la gente debe saber qué es lo que tienes. Esto es factible porque ella está en la empresa pública, porque es funcionaria, pero en la empresa privada... lo que te pasa es que te echan a la calle... Entonces... es todo un proceso, empiezas a hablar, empiezas a mirar por Internet, empiezas a leer, empiezas a ir a alguna conferencia y tal y entonces viene la fase que yo viví de culpabilidad, hostia no me la he creído, es que me estaba diciendo eso y yo sencillamente ino me la creía!"

\section{Del diagnóstico a la acción}

Y de la culpabilidad a la acción, ¿qué hacer? En este momento de la enfermedad Jordi será el apoyo social que nos habla Mishel, para Montse y el colectivo de afectadas y afectados, también en sentido amplio, su experiencia de pareja le lleva a pensar en la experiencia de tantas y tantas familias que posiblemente hayan vivido la misma situación de incertidumbre. De problema personal a problema complejo, de colectivo y la búsqueda de soluciones globales y compromiso político.

"Como no me lo he creído y lo hemos pasado todos muy mal, lo más fácil es pensar que a otra gente le pase lo mismo, yo no soy especial, no soy demasiado diferente de los demás, es perfectamente posible que otros estén pasando por este mismo proceso, entonces empiezo a buscar personas que estén afectadas y veremos si se puede hacer algo, la verdad es que no recuerdo cómo las conocí en un principio, pero nos conocemos y empiezas a hablar y bueno, nos montamos la historia esta de la Iniciativa Legislativa Popular (ILP) para el parlamento, yo en un primer momento estoy bastante apartado, a lo único que me dedico es a ayudar y lo que hago es tratar de conseguir el apoyo de diversas instituciones relevantes dentro de la sociedad civil catalana, yo tenía claro que una ILP con un número suficiente de firmas 
tiene fuerza, pero si va acompañada tendrá más fuerza aún, conseguimos el apoyo de todas las universidades públicas, de la cámara de comercio, del colegio de abogados, en fin, instituciones que tienen su peso y que la clase política reconoce."

La FM es una enfermedad catalogada I'American College of Rheumatology describe en 1990 los criterios diagnósticos y la Organización Mundial de la Salud (OMS) la acepta en 1992; aún con esta descripción, algunos autores como (Burkham, 2006) hablan de la no aceptación por la comunidad científica y civil, la frustración compartida de profesionales y afectados debido a la dificultad del diagnóstico, la ausencia de una evidencia objetiva para ello, la naturaleza crónica de la enfermedad que a la vez se presenta con variabilidad de síntomas difíciles de ser tratados. La falta de evidencias externas, la variabilidad en la presentación del dolor, el cansancio y otras sintomatologías asociadas hacen incomprensible también el fenómeno a ojos de la sociedad en general ¿Quién experimenta las consecuencias de estos desencuentros?

"Nosotros no estamos contra el profesional, no lo podemos estar, son los que nos deben ayudar, sería de tonto quererme enfrentar a ellos; pero estoy en contra de ciertas actitudes, de ciertos profesionales, no puede ser que a una persona que va a buscar ayuda a un servicio de urgencias le digan que es una mal follada iesto no puede ser! estoy para incidir en estas actitudes, por la vía del colegio de médicos, hay otras personas que quieren usar la vía de la demanda, bueno, veremos qué hacemos, pero es que no se puede decir eso a alguien que básicamente está enfermo y viene a pedir su ayuda, esta actitud siempre encontrará mi frontal oposición, lo que no haré será generalizar estas actitudes en todo el colectivo médico, no, no, porque nos hemos encontrado médicos que nos entienden y algunos nos quieren ayudar, pero hay cosas que son tan básicas que hoy día no se puede permitir que alguien, sea de la profesión que sea, que se crea en un pedestal y que se crea capaz de aplastar a quien está debajo de él, no, esto no puede ser, contra estas actitudes me encontrarán siempre en contra y lucharé en todo lo que esté en mi mano, pero 
yo creo que el colectivo médico aunque en gran parte le falta entender realmente cómo puede ayudar a estas personas, pues bien, tendremos que hacer un camino juntos, pero... los necesitamos, es que si a estos enfermos les sacas la ayuda de los profesionales médicos, es que no les quedaría nada..."

\section{El día a día}

La vida sigue, el trabajo propio y el de la compañera, él prefiere cobrar menos a costa de disponer de tiempo en el que llevar la nueva responsabilidad que asume libremente. Reuniones y negociaciones con agentes sociales implicados en el manejo del fenómeno, discursos de competencias profesionales, de contextos de cuidado y dificultades en el diagnóstico y tratamiento; una única finalidad mueve a Jordi, mejorar la situación del colectivo, una más y mejor aceptación de la enfermedad puede contribuir a la adaptación[3].

"Hoy no se diagnostica con la misma alegría que hace 2 o 3 años. No me dirían lo que me están diciendo, que esa energía que dedico en pedir que las unidades funcionen la debería destinar a exigir que sea la primaria la que lleve estos enfermos, y digo... pensamos que el punto final debe ser la primaria, pero ¿cuándo? Cuando tenga la capacidad y los recursos adecuados para ello, mientras tanto, no ¿eh? Mientras tanto necesitamos la ayuda de los expertos de las unidades especializasa, de equipos multidisciplinares; paralelamente a que el profesional se informe, que esté al día y que todo aquel que tenga voluntad e interés de asumir el tema, que lo haga, iperfecto! iNingún problema! ahora bien, hoy por hoy estamos en la mitad del viaje. Yo confío en que llegaremos a tener un marcador homologado a nivel internacional, fiable, que no excluya a nadie que tenga la enfermedad, que la tenga, es decir, que lo diagnostique con toda fiabilidad y no excluya a nadie que sufre una enfermedad, en este momento la primaria podrá hacerse cargo de este colectivo de enfermos, pero ahora no, es mi opinión..."

En este momento de la enfermedad de Montse parece que se da ya una familiaridad de los hechos[4] para ella, su pareja y la familia amplia, para el 
hijo será más difícil. Si hablamos de apoyo social se da en el entorno inmediato, en el entorno más amplio podríamos hablar de una solidaridad implícita pero no explícita, perciben un compartir que no un compromiso social y político. Aquí podemos incorporar un nuevo concepto de Mishel que habla de coherencia de los hechos como la "coherencia existente entre lo esperado y lo experimentado en los hechos que resultan de la enfermedad" ¿qué puede esperar una persona afectada de una enfermedad crónica en un Sistema de salud Universal, en una sociedad democrática, en un estado de bienestar?

"Vaya donde vaya, hable con quien hable siempre encuentro algún familiar, algún conocido de un enfermo, juego con esta ventaja, entre comillas... con toda la pena del mundo ¿he? pero lo tengo comprobado, hay gente que no lo dice abiertamente, pero con la mirada sí, sabes que estás ante alguien que dice, no te lo diré, pero es que yo... algunos te dicen eh por favor, no lo comentes, no lo digas... y ¿cuántos agentes sociales implicados hay? Potencialmente todos, ¿contra qué chocamos? si esto es así ¿por qué no hemos avanzado más? porque hay intereses que no lo permiten, no sé qué, quien o donde, pero algo hay, no lo sé... Si de 10 personas que me dirija encuentro 6 o 7 que conozcan directa o indirectamente una persona enferma... al menos una parte debería luchar a muerte por esa persona, si fuera así no estaríamos donde estamos... a nivel político hay afectación pero no se hace nada para sumarse a la lucha. Antes de las elecciones todo el mundo quería hablar con nosotros, me decía uno... escucha mira, nosotros somos muy sensibles, mi hermana está afectada ¿sabes? A lo que yo le respondí pues no se nota... itú hubieras podido hacer mucho más! ¿Qué has hecho? yo tengo unos medios muy limitados ipero vosotros! si hubiera voluntad política se hubiera avanzado mucho más, no se quiere, ese miedo... ese miedo..."

\section{Una mirada social y política}

Hay un sentimiento de orfandad, hay una asunción de los discursos de la clase dominante, (Fontana, 2012) habla que las clases dominantes, desde la Revolución Francesa y sobre todo a partir de la guerra fría, establecen un pacto político para protegerse ante el miedo a una posible revolución comunista, 
cuando esto parece alejarse de la política global, en la década de los 70 del siglo pasado, se ve que la perspectiva no era establecer un sistema que garantizara un futuro mejor para la humanidad, sino su protección, es así que Krugman, citado por Fontana describe como la gran divergencia[5], pacto de bienestar para a la vez protegerse de revoluciones, cuando esto parece que se aleja, que es el momento actual, ya no se precisan concesiones, sólo el mercado libre como discurso y acción.

"Hay un claro componente económico, como que hay una afectación tan brutal saben que ni la seguridad social ni nadie puede hacerse cargo económicamente de este colectivo de enfermos que no para de crecer. Yo lo comparo un poco con el problema de que cada vez hay más jubilados y menos gente trabajando y esto llega a un punto que no es sostenible, si cada vez tenemos más enfermos, cada vez tenemos más problemas en los entornos laborales porque la gente que está afectada y no puede hacer su trabajo, cada vez tendremos que pagar más incapacitados. Eso no lo podemos reconocer de ninguna manera, porque nos genera un problema económico de primera magnitud, creo que es eso, creo que el problema real y de fondo es éste, se olvidan de que si habláramos entre todos..."

Jordi se mueve hábilmente en reuniones con responsables políticos, profesionales de la salud o del empresariado, a cada colectivo con la misma demanda o exigencia adaptada a las responsabilidades concretas... su compromiso lo asume con tesón.

"Ayer tuvimos dos reuniones, una con la FOCAP[6] y la otra con el Fomento del Trabajo y fue aquí que planteamos estas cuestiones, estas personas están enfermas ¿verdad? ¿Qué quiere que hagamos? lo que no quiero es que las echen a la calle por bajo rendimiento, tienen el mismo derecho a la vida que cualquier otra persona enferma. Usted no tiene que pagar, pero tenemos que buscar la forma de adaptar el horario y el puesto de trabajo... como sea, pero esta persona que tiene ganas de trabajar, cada vez que se levanta de la cama es una lucha para ella, cada mañana, yo cuando veo a mi mujer cada mañana contenta de levantarse, yo la veo $y$, a veces, se pasa 
10 minutos sentada antes de levantarse, pero aún así va, va al trabajo. Esto es un valor para la empresa, van a trabajar ino por el sueldo que cobran! sino porque necesitan sentirse útiles, necesitan trabajar... habrá quien por su afectación jamás podrá, pero quien pueda y mientras pueda... y desde todos los agentes sociales, los sindicatos también, en los convenios, pactar condiciones dignas de trabajo. Aquí todo el mundo tiene que hacer lo que esté en su mano para ayudar, porque cada vez hay más e ignorando el problema no se soluciona."

\section{El sistema familiar}

Es difícil convivir con la enfermedad crónica, una enfermedad poco visible a ojos profanos, y a la vez, sentida y vivida con intensidad para los propios y cercanos, el ponerle nombre ayuda a situarse. El tiempo permite a Jordi y Montse familiarizarse con los hechos y gestionar la incertidumbre, a la vez que se avanza él a posibles elementos del entorno social que pueden perturbar un equilibrio inestable; en este sentido a menudo se presentan remedios curativos que pueden llegar a confundir, sobre todo por el deseo, la necesidad de buscar alivio al dolor, el malestar e incapacidad funcional, parece difícil de creer, pero en pleno siglo XXI siguen existiendo charlatanes o salvadores que se presentan como capaces de curar la enfermedad, que obvian el conocimiento científico, al que Jordi sí da valor.

"Cuando el diagnóstico, existe la sensación de alivio ya sabemos dónde estamos, pero, ¿ahora qué? no se cura, y pienso en toda esta gente, esta pandilla de vividores que te ofrecen remedios milagrosos y que te venden como que te pueden llegar a curar, tenemos que vigilar. Yo siempre he pensado que puedes meterte a fondo en un tema cuando lo conoces, si no lo conoces lo más probable es que o te engañen o que te estrelles y pensé, si me estrello yo, no pasa nada, pero si se estrella ella todavía será peor y cuidado con las falsas expectativas porque hay mucho desaprensivo por ahí, que prometen curación, esto aún hoy en día pasa, el otro día en la feria de entidades de Pueblo Seco, aquí en Barcelona en una mañana vinieron 4 individuos a ofrecer sus servicios para curar a estos enfermos (...) mi reacción fue, la tengo que proteger de los 
desaprensivos y conseguir que en el trabajo no lo pase tan mal."

El sistema familiar tiene como eje la vivencia de la enfermedad, una enfermedad que como ya se ha avanzado, tiene pocas manifestaciones visibles y ningún marcador objetivo de diagnóstico, lo que la hace más difícil de ser aceptada, a la vez esta aceptación es esencial para que se dé el apoyo social, Montse necesita que su hijo acepte la enfermedad, pueda percibir su apoyo, le permita interpretar el significado de su propia enfermedad y le facilite gestionar su nivel de incertidumbre; en este sentido Jordi será pieza clave.

"Y el hijo no tiene aún muy claro, a los 20 años, que su madre no se aproveche de la enfermedad, y lo vivimos con enfrentamientos yo con él, lo cojo aparte y le digo, escucha ¿sabes qué pasa? que tu padre no está haciendo todo esto para nada... para que vengas tú aquí y te lo cargues todo, que le grites a tu madre... los gritos, fuera de casa, coges la puerta, sales y chillas a quien quieras, pero de puertas adentro a nadie, aquí en casa no se grita, no hay competición ninguna, aquí en casa lo que hay es colaboración para salir adelante, con una charla así fue suficiente. Pero sé que para él es difícil, él ve mis esfuerzos para que su madre esté mejor, pero... se le ha procurado explicar ¿a ti te ha faltado algo? ¿Cuando has pedido una cosa, si es razonable, lo has tenido? No te ha faltado una escuela en condiciones, y tal ¿qué más quieres? todavía no tiene los años, todavía le falta, estoy convencido... y con la madre... se frena, porque ya hemos tenido un par de conversaciones serias, se frena, pero por dentro su yo juraría que todavía cree que, no de forma permanente, pero sí que hay momentos que cree que su madre se aprovecha y ella ilo vive fatal! Y yo icabreado! Y él lo vive... hemos hablado alguna vez y él dice que lo que le pasa a mamá es una gran putada y yo le digo, pues sí, es una putada pero ¿qué hacemos? Hacemos lo que podemos y sin demasiadas esperanzas de solución, porque aún falta que la ciencia la encuentre. Lo hemos intentado incorporar en la asociación, no quiere... pero bueno, ahí estamos. Algunos chavales de hoy en día... no se puede generalizar, pero tienen 30 años y no han madurado, queda mal decirlo, pero no es como nosotros que a los 25 ya teníamos las cosas claras, ya llegará." 


\section{Las asociaciones}

Las asociaciones como recurso y apoyo, ellas más que nadie saben del fenómeno desde la experiencia, ellas saben de promover charlas de interés y actividades adaptadas, ellas conocen los puntos fuertes y débiles, ellas jamás exigirán aquello que, de antemano, saben que no pueden llevar a cabo sus asociadas. Las asociaciones pueden jugar un papel importante cuando el sistema de salud presenta fragilidad, para complementar su acción. Compartir con otras personas la vivencia de la enfermedad, piensan, será un nuevo elemento para contribuir a la adaptación harmoniosa.

"Entonces dije, habrá alguna asociación de enfermos, si en Internet hay tanta información, alguna habrá y contacté con la ACAF[7], así que le dije a mi mujer que se apuntara... es básico y fundamental que un enfermo comparta la experiencia que tiene con otros que están como él, es la única forma de ver que no es una que se lo hace, que no se está sola y compartiendo experiencias, haciendo grupos de ayuda mutua, músico terapia... haciendo cosas, el mismo grupo de personas que se conocen con el paraguas de la asociación, a la vez es un filtro para evitar estos desaprensivos que dan falsas expectativas y poco a poco se van encontrando mejor, el componente psicológico no es tan agresivo, que hagan depresiones y esas cosas, es muy positivo. $Y$ de las primeras sensaciones de quererla proteger a buscar una asociación, vas y te apuntas ¿quieres decir que sí? ¿Me acompañarás? iSí! ya está y a partir de entonces pues claro..."

Jordi habla de la necesidad de las asociaciones, no como grupo excluyente, como lobby o estigmatización[8], sino como necesidad y recurso vital para las personas afectadas a la vez que reconoce que para la administración también es complejo, las asociaciones complementan las actuaciones institucionales, no las deben suplir, a la vez se deben aceptar mutuamente, la finalidad es común, no se trata ni de competir ni de trabajar en sentidos opuestos, hacer política pero no política partidista y una vez más el entendimiento y las sinergias son esenciales. 
"El movimiento asociativo debe existir, hay cosas en que las administraciones no podrán llegar nunca. Algunas asociaciones están haciendo un trabajo muy interesante, quizás otras no tanto. Me preocupa que algunas actúen excesivamente influenciadas por el gobierno anterior, ahora no sé cómo está la cosa, el tiempo lo dirá. Para muchas enfermas sólo el ir al local de la asociación a 30 minutos les es un gran esfuerzo... en una reunión una profesional decía: se apuntan a cursos de auto ayuda y eso, y no hay ni una que los acabe, bueno... y ¿por qué no los acaban? y tú profesional ¿̇o preguntas? No vamos bien... no acaban iporque no pueden! ¿No será que habéis planificado estas actividades como si fueran para personas sin esta enfermedad? Fue en una reunión de gerencia territorial de la zona de Bellvitge, eran pesos pesados, es que les tenemos que pedir que cuando se apunten cumplan con la expectativa de cubrir todo el curso, que no se ausenten... escuchen ¿qué me están diciendo ahora? es que alguien que me dice eso... me está diciendo que no conoce la enfermedad. No es que se cierren única y exclusivamente en la asociación, no es una limitación voluntaria sino que la limitación es la enfermedad, cuando pueden van con la familia, cuando pueden, ellas quieren hacer vida normal, pero no pueden, es muy complicado..."

Hemos visto la necesidad que haya profesionales conocedores de la enfermedad crónica, de su complejidad y de su vivencia, hemos visto también el papel que juegan las asociaciones y también sabemos de la existencia de salvadores o sanadores que se presentan con tratamientos milagrosos, la pregunta que nos hacemos es si Jordi cree que en las asociaciones deberían o no participar profesionales de la salud y si la respuesta es positiva, qué papel les asignaría.

"Probablemente tendrían que haber profesionales en las asociaciones, pero no de manera profesional, sino vocacional, éste a veces tiende a decir lo que le conviene a cada uno, porque lo digo yo... mmmm no, aquí no vamos bien, en cambio, si hay algún componente vocacional no es lo mismo, es otra relación... es que la relación profesional-paciente en este ámbito está muy deteriorada, hay mucha desconfianza mutua, no hay que engañarse ¿Poner 
profesionales en las asociaciones? Sí, si hay este componente de vocación, de querer ayudar, de hacer algo a cambio de nada para esta gente, si no, no, es que si no pueden hacer más daño..."

Emerge una sonrisa de satisfacción en su rostro apesadumbrado, eran sus inicios de compromiso con la causa, era un querer reparar los años de sufrimiento, incomprensión e incertidumbre compartida, de culpabilidad, según sus palabras; se inicia con una responsabilidad en segunda línea aprovechando sus conocimientos de abogacía y sus contextos habituales de trabajo en la universidad. Habla en plural aunque sé que a menudo le toca moverse solo o con escasa compañía, compañía fiel pero insuficiente ante la magnitud del fenómeno, ante el número de afectados y afectadas, a nivel del estado español se diagnostican anualmente 120.000 nuevos casos y paradójicamente será la derecha quien muestre sensibilidad hacia este tema, quien plantee esta cuestión a nivel estatal, aunque no olvidemos que está en la oposición, tiempo tendremos ahora de ver su acción en el gobierno. Es así que pasará de la asociación de afectadas a la asociación de familiares, Jordi transforma la culpabilidad de los años de incomprensión en energía para la solidaridad y la ayuda, si me estrello yo no pasa nada, nos ha dicho una y otra vez, lo que no desea es que ella, su mujer añada, al malestar de la enfermedad, una nueva derrota y conocedor de su experiencia, piensa en hacerla más llevadera para otros y otras.

"Vivo un poco desde la distancia toda la negociación, todavía no formaba parte del núcleo de esta gente que está trabajando y... bien, a partir de aquí una vez se acaba todo y sale la resolución en mayo de 2008 nos planteamos montar una asociación de familiares, creemos que falta iy la montamos! hacemos todos los trámites administrativos legales, los necesarios, montamos una página web y empezamos a caminar, ahora estamos trabajando para hacer crecer esta asociación con el objetivo de tener fuerza suficiente para que nos escuchen. Pero algo habremos hecho mal ya que hemos conseguido poca implicación, nos movemos por Internet y quizás no todo el público al que nos dirigimos usa estas tecnologías, la gente también está muy atareada y tiene muchos problemas, la vida está muy difícil, yo tengo las mañanas libres, otros 
cobraran más, pero yo puedo dedicar este tiempo libre... pero otras cosas las hemos hecho bien, fuimos capaces de llenar escenarios como el pabellón de la ONCE, también en la Illa Diagonal, cuando los llamamos que vengan a hacer acto de presencia ante las administraciones o ante la sociedad, sí que vienen los familiares, de la mano de los enfermos..."

\section{El ocio}

Una vida dedicada al trabajo de cuidado, al asalariado y al solidario, ¿quedará tiempo para el ocio? Y éste ¿atiende al antes y al después de la enfermedad, acepta una programación, queda caja para satisfacerlo? ¿Qué pasa con las amistades? ¿Se puede hacer un trabajo activo para encontrar la solidaridad y el apoyo social más allá de la familia? El ser humano, según Mishel como sistema bio-psico-social, con interacción y partícipe del medio, que necesita cubrir aspectos de una vida amplia y compleja para vivir en salud, para re equilibrarse y vivir en harmonía.

"La gente entiende y acepta las cosas razonables, lo que no entiende es lo que desconoce, la ignorancia hace mucho daño, lo que provoca es miedo y desconfianza, pero si tú les explicas qué es lo que les está pasando lo entienden y la relación que tenemos con los amigos viene de años y no hay ningún problema, al revés, a veces nos reunimos y pobre de ella si se le ocurre hacer algo. Pero a nivel de ocio vamos muy justos... nuestro nivel adquisitivo no es muy alto, viajar no lo hacemos demasiado, lo típico, ir de paseo, caminar mucho tampoco... si vamos al cine no se siente bien, en fin... las cosas normales y espaciadas en el tiempo, porque al igual que no tienes agenda para las tareas diarias, tampoco tienes agenda para el ocio, tú no puedes decir, saco entradas para el teatro que hacen el domingo, porque probablemente ese domingo no podrá ni salir de casa, esto ya nos ha pasado más de una vez, si cuando nosotros decimos que no tenemos agenda o que no podemos hacer agenda también abarca el tema del ocio, tenemos que hacer aquello que no necesita programación previa icuidado con programar 15 días de vacaciones! porque si no está bien... es totalmente imprevisible, no se relaciona con nada, no puedo ni puede controlar los picos, no, no, cuando se presenta, se presenta 
y ya está."

\section{El futuro}

Hemos hablado del pasado, y del presente, nos queda ver como se piensa el futuro, como se imagina, cómo se percibe, se piensa en él o el presente es tan presente que ocupa el espacio del futuro ¿Hay pensamientos, afirmaciones, que podamos interpretar como que se da una nueva perspectiva de vida[9]? ¿O se manifiesta una incertidumbre como riesgo?

"Por una parte espero que mi hijo crezca y comprenda, pero aparte de esto... iNO LO SÉ! No lo sé... Seguramente seguiré siendo tan terco como hoy y espero que la ciencia médica aporte más soluciones de las que ha aportado hasta ahora y espero de la clase política que se conciencie más y ayuden más y cumplan su palabra de que no volveremos a estar nunca más solos como se dijo en el parlamento de Cataluña iNo lo sé! no lo sé, si fuéramos capaces de hacer lo que he dicho de conseguir que todos los agentes sociales implicados aportaran su fuerza para encontrar una solución, si fuéramos capaces de sentarnos todos en una mesa el tiempo necesario para encontrar la forma de ayudar a esta gente, tendríamos un futuro esperanzador, si no somos capaces de hacer esto, continuaremos como hasta ahora. Me gustaría pensar, que se pueda sumar mucha más gente a esta lucha, que seamos capaces entre todos de decir bueno, es que hasta aquí hemos llegado, debemos encontrar una solución y generar las voluntades necesarias, dejándonos de desconfianzas y de otras historias y afirmar que esta gente se merece que no nos levantemos hasta encontrar la forma para que su vida, sino normal, pueda ser comparable a cualquier otra persona que sufre una enfermedad objetivable con el diagnóstico, es que con eso nos conformamos, porque si el único problema es no tener un diagnóstico objetivo no es culpa nuestra... es que es tan fácil como eso.... es que el profesional médico tiene dificultades aquí pero, no es culpa del enfermo..." 


\section{DISCUSIÓN}

Haciendo una lectura crítica y analítica de la narrativa podemos iniciar diciendo que en el sistema familiar de una persona afectada de fibromialgia es esta enfermedad quien pivota como eje de las relaciones y las actuaciones, sean en el ámbito privado o el público. La agenda sirve para anotar las cosas pendientes, pero, evidentemente, no para marcar los días o las horas en las que llevarlo a cabo, sea un trabajo, una compra o unas vacaciones, la crisis se presenta sin previo aviso y es ella la que ocupa y llena los espacios, evidentemente, sin picar a la puerta, sin pedir entrar, sin preguntar sobre su oportunidad.

Seguir diciendo que el sistema de salud atiende en general las demandas, pero se percibe un profundo abismo, una distancia que parece insalvable entre afectados y afectadas e instituciones y profesionales de la salud, por lo que se refiere al médico, sujeto reconocido como esencial, diferencia dos tipos de actitudes en ellos, las profesionales y de ayuda, por una parte y las faltas de educación y consecuentemente no profesionales, de la otra, a la espera de encontrar un marcador objetivo que aporte credibilidad a la enfermedad. Enfermería ausente, demanda de equipos multidisciplinares en los que creemos tener papel activo y un camino a recorrer hasta poder llegar a un cuidado y tratamiento en la primaria y las unidades especializadas.

Por lo que se refiere a los agentes sociales implicados se muestra también el doble discurso, el institucional y formal y el personal, el que se da a corta distancia que se percibe con el lenguaje no verbal, no obstante, éste, no se traduce en las políticas concretas. Mientras tanto el malestar, el dolor y el sistema familiar que se resiente en su globalidad.

Atendiendo a los objetivos debemos pensar en cómo, a partir de la narrativa, describimos unos diagnósticos de enfermería que nos encaminen a ayudar a Montse y su sistema familiar. Mishel nos habla, por una parte, de atender a los pequeños detalles que preocupan a las personas a las que cuidamos, de esta forma, ellas mismas, pueden encontrar un sentido a la 
experiencia que viven; por otra parte, sigue diciendo que las enfermeras deben llevar a cabo una valoración exhaustiva del nivel de incertidumbre para poder intervenir de forma que una incertidumbre percibida como riesgo pueda convertirse en incertidumbre vivida como oportunidad, primer paso para una adaptación harmónica, una nueva perspectiva de vida y una autoridad con credibilidad, a la vez que se contemplan los diferentes recursos y el apoyo social.

A partir de aquí es obvio que no vamos a formular diagnósticos de enfermería atendiendo a taxonomías estandarizadas, sino plantear problemas de competencia enfermera, que emergen de la narrativa y que varían según se plantea la temporalidad de la propia narrativa.

Podemos ver así un nivel de incertidumbre muy elevado, tanto para Montse como para Jordi, en el inicio del malestar y cuando todavía no hay un diagnóstico clínico, enfermería ¿debe esperar a cuidar cuando hay un diagnostico médico? O puede hacer una valoración atendiendo a las aéreas de competencia propia y atendiendo al concepto de ser humano que nos aporta el mismo modelo, como sistema abierto y multidimensional. Podemos atender también a lo que nos dice (Valverde, 2008) en la medida de atender simultáneamente a los conocimientos científicos y a los significados del paciente, la misma autora habla de la narrativa como nexo para la relación de ayuda.

No percibimos apenas credibilidad con autoridad, sería difícil cuidar sin un reconocimiento, es posible que debamos trabajar para asumir un cuidado profesional que se puede dar en la comunidad. Simultáneamente y para conseguirlo actuar globalmente.

No sabemos si es preciso explicitar de forma detallada problemas que han emergido en el sistema familiar susceptibles de ser compartidos con enfermería para contribuir a su resolución; las aéreas a las que nos referimos son: Incertidumbre ante el malestar percibido, en los diferentes momentos y diferentes niveles. La adaptación harmónica entendida como comportamiento 
que se debe modificar, debido al malestar y para alcanzar una nueva perspectiva de vida, no ya como imperativo, por la imposibilidad de llevar a cabo una vida como la anterior del malestar, sino porque se ha alcanzado una familiaridad de los hechos, un reconocimiento de las claves del malestar que influyen de nuevo en el nivel de incertidumbre.

Emerge un bucle susceptible de ser contemplado por enfermería, pensamos que con perspectivas del siglo XXI, en el paradigma de la complejidad y de la transformación, adoptando modelos que contemplen una visión global de los fenómenos de salud, aunque en el momento que nos toca vivir y que la propia educación y las universidades se presentan como una amenaza para el sistema de libre empresa y comercio que defienden la minoría dominante, dependerá de lo que hagamos en el presente, para que una nueva mirada pueda intervenir en los cuidados profesionales, a la vez que el análisis crítico y la reflexión, nos acerquen a un nuevo conocimiento científico.

\section{BIBLIOGRAFÍA}

- Bailey, D. J., \& Stewart, J. (2005). Merle Mishel, la incertidumbre frente a la enfermedad, en , 5a. Ed. , (). A A. A. Marriner, Modelos y teorías en enfermería (p. 561-584). Mosby.

- Burkham, J. (2006). Fibromialgia: un síndrome de dolor crónico, en, , 7a. Ed. () . A J. E. Harris, Tratado de.Reumatología (p. 530-540). España: Elseiver.

- Fontana, J. (8 / Febrero / 2012). Más allá de la crisis. Consultat el 21 / Marzo / 2012, a Rebelion: http://www.rebelion.org/noticias/2012/2/144304.pdf

- Guerreiro, D. T. (2008). Lla narrativa em investigación em enfermería . In: M. D. Lenise do Prado, Investigación cualitativa en enfermería: contexto y bases conceptuales (pp. 195-211). Washington: Organización Panamericana de la Salud. Serie PALTEX. 
- Kérouac, S. (2007). El Pensamiento Enfermero. Barcelona: Masson S A.

- Valverde, C. (2008). Enfermería centrada en los Significados del Paciente $\AA$. Un modelo basado en la narrativa y en la ética del otro. Index de Enfermería. Consultado el 22 / Marzo / 2012, a.: http://www.index-f.com/index-enfermeria/v17n3/1578.php

- Goffman, E. (1995). Estigma. La identidad deteriorada. Buenos Aires: Amorrortu editores.

[1] Apoyo familiar, amistades y de la sociedad en sentido amplio

[2] Grado de confianza que las personas tienen respecto a los profesionales de la salud que les atienden

[3] Como resultado de los esfuerzo de afrontamiento e interpretación de la incertidumbre como oportunidad

[4] Mishel habla que las personas son capaces de reconocer las claves de la enfermedad

[5] Proceso por el cual se da el enriquecimiento del 1\% de la población y el empobrecimiento del resto

[6] Fòrum Català d'Atenció Primària

[7] Asociación Catalana de Afectados de Fibromialgia

[8] En la perspectiva de desacreditados que describe Goffman (1995: 14)

[9] Según Mishel significa la nueva reformulación y el nuevo sentido del orden de las cosas, llegando a aceptar la incertidumbre como inherente a la vida, se percibe así la incertidumbre como oportunidad y no como riesgo. 